\title{
Reflexões sobre o uso do GeoGebra e o ensino de Geometria Euclidiana
}

\section{GeoGebra and the teaching of Euclidian Geometry}

\begin{abstract}
Resumo: O artigo relata uma pesquisa com trinta e dois professores de Matemática, participantes de um minicurso que abordou o uso do GeoGebra e alguns aspectos da Geometria Euclidiana Plana. O objetivo deste artigo é relatar o uso que os professores fazem dos recursos tecnológicos presentes nas escolas e qual a importância que eles atribuem ao software GeoGebra, além de observar os conhecimentos dos professores sobre alguns conteúdos de Geometria Euclidiana Plana e a relação que eles estabelecem sobre saber Geometria para utilizar o GeoGebra. A pesquisa tem cunho qualitativo e para atingir os objetivos utilizamos um questionário, gravação em áudio e observações. Dentre os resultados destacamos a insegurança e o fascínio que os professores sentem na utilização do GeoGebra, a falta de percepção de que para ensinar Geometria não basta ter um software, ou seja, também é necessário conhecer os conceitos geométricos, além de lacunas no conhecimento de tais conteúdos.

Palavras-chave: Educação Matemática. Ensino de Geometria. Formação de Professores. GeoGebra.
\end{abstract}

Abstract: The article reports com a study with thirty-two Math teachers participating in a course on the use of GeoGebra and the study of Euclid's plane geometry is described. Information was collected on the use that teachers deploy on current technological resources in the classroom and the importance they attribute to the GeoGebra software. Teachers' knowledge on contents of Euclidian geometry and the relationship they establish on geometrical knowledge in their use of GeoGebra were also analyzed. The qualitative research also included a questionnaire, recordings and notes. Results enhance the insecurity and the fascination that teachers feel when using GeoGebra and their lack of perception that the use of the software in the teaching of geometry is not enough. Rather, it is highly necessary to know geometrical concepts and the gaps in the knowledge of contents.

Keywords: Math Education. Teaching of Geometry. Teachers' Formation. GeoGebra.

LOVIS, Karla Aparecida; FRANCO, Valdeni Soliani. Reflexões sobre o uso do GeoGebra e o ensino de Geometria Euclidiana. Informática na Educação: teoria e prática, Porto Alegre, v. 16, n. 1, p. 149-160, jan./jun. 2013.

\author{
Karla Aparecida Lovis \\ Valdeni Soliani Franco \\ Universidade Estadual de Maringá
}

\section{Introdução}

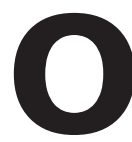

interesse pela pesquisa surgiu, principalmente, das nossas experiências em cursos de formação continuada, palestras e conversas com professores de Matemática. Em vários momentos fomos questionados se realmente era possível utilizar um software para ensinar algum conteúdo de Matemática. Sempre defendíamos que era possível, no entanto, algumas condições se faziam necessárias: um software adequado, conhecimento do software e do conteúdo a ser ministrado, entre outros. Entre as justificativas que predominavam nas falas da maioria dos professores, era que eles não utilizavam os softwares por não os conhecerem e porque não sabiam como iriam ensinar um conteúdo usando um software; além da falta de suporte técnico e equipamentos adequados e em condições de uso. Em nenhum momento os professores relatavam que não utilizavam por não terem conhecimento ou segurança nos conceitos ma- 
temáticos. Diante deste contexto, resolvemos investigar as relações entre o uso do GeoGebra e o ensino de Geometria Euclidiana.

A investigação foi realizada durante o minicurso "O GeoGebra e a Geometria Euclidiana Plana", oferecido para trinta e dois professores de Matemática que participaram do Programa de Desenvolvimento Educacional - $\mathrm{PDE}^{1}$ na Universidade Estadual de Maringá - UEM - no ano do 2011. O minicurso teve duração de 16 horas e foi ministrado por um dos autores do artigo. O objetivo do minicurso foi trabalhar a Geometria Euclidiana Plana, usando o GeoGebra, e mostrar como é possível utilizá-lo para ensinar Geometria aos alunos, nas escolas.

Os objetivos da pesquisa consistem em averiguar se os professores fazem uso dos recursos tecnológicos presentes nas escolas ${ }^{2}$, e qual a importância que eles atribuem ao uso do GeoGebra. Também observamos os conhecimentos dos professores sobre alguns conteúdos de Geometria Euclidiana e a relação que eles estabelecem entre saber Geometria para utilizar o GeoGebra.

Nossa investigação apóia-se numa abordagem de cunho qualitativo; ela é um processo formal e sistemático desenvolvido para descobrir respostas por meio de procedimentos científicos. Lüdke e André (1986) expõem que para realizarmos uma pesquisa qualitativa é preciso promover o confronto entre os dados,

\footnotetext{
${ }^{1}$ O Programa de Desenvolvimento Educacional - PDE - do Estado do Paraná está vinculado a SEED com uma parceria com as Universidades Públicas Estaduais e Federais do Paraná e a Secretaria de Estado da Ciência, Tecnologia e Ensino Superior. O PDE tem como objetivo o aperfeiçoamento e a qualificação do professor da Rede Estadual de Educação Básica do Paraná. 2 As escolas estaduais do Estado do Paraná possuem laboratório de informática com os seguintes softwares disponíveis: GeoGebra, Régua e Compasso e Dr Geo. As salas de aula estão equipadas com um televisor de 29 polegadas, com entradas para VHS, DVD, cartão de memória e pen drive e saídas para caixas de som e projetor multimídia. Por meio dos dispositivos, citados acima, é possível transferir dados e informações que podem ser visualizados na tela da TV e de microcomputadores.
}

as evidências, as informações coletadas sobre determinado assunto e o conhecimento teórico acumulado a respeito dele. Analisar os dados de forma qualitativa significa "'trabalhar' todo material obtido durante a pesquisa, ou seja, os relatos de observação, as transcrições de entrevista, as análises de documentos e as demais informações disponíveis" (LÜDKE; ANDRÉ, 1986, p. 45).

Para atingir os objetivos da pesquisa utilizamos os seguintes instrumentos de coleta de dados: gravação em áudio das falas dos professores, um questionário ${ }^{3}$ e observações realizadas durante o minicurso. O objetivo do questionário foi obter algumas informações gerais sobre os professores, investigar com que frequência eles fazem uso de tecnologias, o que eles pensam sobre o aprendizado de Geometria por meio do GeoGebra e investigar alguns conhecimentos referentes à Geometria Euclidiana Plana. A finalidade das gravações e das observações foi contribuir na análise e discussão dos dados obtidos no questionário.

Os sujeitos da pesquisa são trinta e dois professores de Matemática que atuam nas séries finais do Ensino Fundamental e Ensino Médio, cuja formação é: Ciências habilitação em Matemática (dezesseis professores), formação em Matemática (nove professores), formação em Biologia (um professor) e os demais (seis professores) não informaram o curso que possuem. Dentre os professores, dois se formaram em uma instituição pública e os demais em instituições particulares; o ano de formação desses professores aconteceu no período de 1973 até 1994. 


\section{0 professor e o uso dos recursos tecnológicos presentes nas escolas}

Nas últimas décadas muito se tem falado em novas tecnologias - também designadas Tecnologias de Informação e Comunicação (TICs) - e da inserção desses recursos nas escolas. Ao falarmos de novas tecnologias, fica a pergunta: quem são as velhas tecnologias? Na disciplina de Matemática, quando se discute essa inclusão, muitas vezes não nos damos conta de que o lápis, o papel, o transferidor, o compasso, também são tecnologias, novas ou não, mas que também estão presentes no contexto escolar. Essas ferramentas ainda são importantes para o ensino e a aprendizagem da Matemática, em particular da Geometria.

Com relação ao uso de novas tecnologias - computadores, projetor multimídia, internet, entre outros, parece haver uma resistência natural ou certa idolatria. A introdução de toda tecnologia traz consigo novos temores, ansiedades e fantasias. Carneiro (2002) expõe que:

Aos poucos, esses sentimentos vão sendo substituídos por uma aceitação pouco refletida e à medida que essas tecnologias vão se tornando mais familiares e acessíveis, percebemos que tanto uma euforia quanto a resistência cegas tendem a obscurecer a reflexão crítica necessária sobre tais avanços (CARNEIRO, 2002, p. 11).

As mudanças tecnológicas, em geral, são incorporadas no nosso dia a dia que nem refletimos ou questionamos a sua necessidade. Os professores, tanto da Educação Básica quanto do Ensino Superior, devem refletir sobre as transformações que uma tecnologia confere ao contexto escolar. Encontramo-nos em um período de transição, porque convivemos com pessoas que nasceram na era digital, que, se- gundo Palfrey e Gasser (2011), é quando surgem os computadores portáteis, e com os chamados imigrantes digitais, que são as pessoas que nasceram antes da era digital. Para Palfrey e Gasser (2011), todo processo de mudança ou transição traz consigo inseguranças, desafios, e com isso a necessidade de novos estudos e metodologias.

Como já dissemos anteriormente, um dos objetivos do nosso trabalho é averiguar se os professores pesquisados fazem uso dos recursos tecnológicos presentes nas escolas. Para responder este objetivo perguntamos aos professores com que frequência eles faziam atividades no laboratório, com os alunos. Dentre as respostas, quatorze professores relataram que nunca utilizaram o laboratório de informática e dezoito utilizam raramente. Com relação ao uso de tecnologias na sala de aula, tanto as consideradas velhas quanto as novas (computador, projetor multimídia, régua, compasso, entre outros), nove professores relataram que nunca as utilizam; dezoito utilizam raramente e apenas cinco responderam que utilizam com frequência alguma tecnologia.

Apesar das dificuldades e das incertezas que permeiam o ambiente escolar, é recomendável que o professor abandone a zona de conforto e se aventure na zona de risco. Borba e Penteado (2001) destacam que os professores,

[...] não se movimentam em direção a um território desconhecido. Muitos reconhecem que a forma como estão atuando não favorece a aprendizagem dos alunos e possuem um discurso que indica que gostariam que fosse diferente. Porém, no nível da sua prática, não conseguem se movimentar para mudar aquilo que não os agrada (BORBA; PENTEADO, 2001, p. 54).

Os acontecimentos que ocorrem na zona de conforto são mais previsíveis e os professores 
têm dificuldades em avançar para a "zona de risco na qual é preciso avaliar constantemente as consequências das ações propostas" (BORBA; PENTEADO, 2001, p. 54-5).

Ribeiro e Ponte (2000) destacam que a integração de novas tecnologias nas práticas educativas parece ser um processo indefinido, não pela lentidão, mas pela falta de rumo. Diante disso, acreditamos ser essencial que os professores tenham acesso a orientações metodológicas inovadoras e adequadas para fazer uso das novas tecnologias.

Perceber o laboratório de informática como uma sala de aula, que precisa de um professor que oriente, e um contexto de aprendizagem, é um importante passo no processo de utilização dos recursos disponíveis em favor da educação. Penteado (1999) expõe que:

[...] em geral, o professor enfrenta os desafios impostos pela profissão e busca criar alternativas, porém a introdução do computador na escola altera os padrões nos quais ele usualmente desenvolve sua prática. São alterações no âmbito das emoções, das relações e condições de trabalho, da dinâmica da aula, da reorganização do currículo, entre outras (PENTEADO, 1999, p. 298).

Para que o professor possa utilizar os recursos tecnológicos presentes nas escolas é preciso que ele conheça as possibilidades educacionais destes recursos, uma vez que a sua disponibilidade não garante que ele será utilizado em benefício da educação. Esse fato aponta para uma necessidade de investir na formação e aperfeiçoamento do professor de forma continuada. A formação continuada parece ser um dos suportes mais importantes para o desenvolvimento das competências e saberes relacionados às novas tecnologias $e$ ao seu uso na prática pedagógica.

Quanto aos cursos e capacitações, sobre o uso das tecnologias disponíveis nas escolas, a maioria dos professores - vinte e dois - respondeu que raramente tinham acesso a esse tipo de formação; quatro professores responderam nunca terem feito algum curso e apenas seis professores relataram que participam frequentemente de cursos de capacitação.

Sem formação adequada e sem possibilidades de interagir com os ambientes dos softwares fica difícil para o professor conseguir incorporar essas ferramentas nas suas aulas. Ao considerar o período de formação dos professores - de 1973 a 1994 - supomos que estes não tiveram contato com microcomputadores durante a sua formação inicial e até mesmo nas suas atividades diárias, uma vez que a popularização da interface Windows, por exemplo, aconteceu a partir da década de $1990 \mathrm{com}$ a versão Windows-3. Os computadores pessoais tornaram-se mais populares e acessíveis há poucos anos, o que nos faz pensar que a maioria dos professores não teve contato com essa máquina, durante a formação inicial, e isso contribui para que eles sintam-se ainda mais intimidados pelo computador.

\section{0 ensino de geometria e os soft- wares geométricos}

Parece consenso entre os educadores matemáticos a importância do ensino de Geometria. Lorenzato (1995) destaca o fato da Geometria exigir do aluno uma maneira específica de raciocinar e que as questões geométricas exigem "uma leitura diferente da Aritmética ou Álgebra, na medida em que, para resolvê-las, é preciso ter percepção geométrica, raciocínio geométrico e linguagem geométrica, fatores essenciais na relação real/formal" (LORENZATO, 1995, p. 5). 
Os conteúdos de Geometria são recomendados pelos Parâmetros Curriculares Nacionais (PCN) e nas Diretrizes Estaduais de Educação (DCE) de Matemática do Estado do Paraná. Os PCN (1998) para o terceiro e quarto ciclos do ensino fundamental apontam que,

Os conceitos geométricos constituem parte importante do currículo de Matemática no ensino fundamental, porque, por meio deles, o aluno desenvolve um tipo especial de pensamento que lhe permite compreender, descrever e representar, de forma organizada, o mundo em que vive (BRASIL, 1998, p. 51).

Os PCN também destacam que o professor deve desenvolver situações que explorem as construções geométricas com régua e compasso, a visualização e aplicações de propriedades das figuras.

As DCE (PARANÁ, 2008) trazem o conteúdo estruturante Geometrias que se desdobra em Geometria Plana, Geometria Espacial, Geometria Analítica e noções básicas de Geometrias não-Euclidianas. De acordo com as DCE, o aluno do ensino fundamental deve ter o espaço como referência de tal modo que consiga analisá-lo, perceber seus objetos e por fim representá-lo. No ensino médio, o aluno deve aprofundar os conceitos de Geometria Plana e Espacial, bem como ter contato com a Geometria Analítica e com noções de Geometrias não-Euclidianas. Por fim, as DCE apontam que "os conceitos destes conteúdos são fundamentais para que o aluno do Ensino Médio amplie seu conhecimento e pensamento geométrico" (PARANÁ, 2008, p. 57).

O ensino de Geometria envolve construções geométricas, o estudo das figuras planas, dos sólidos geométricos, ideias de paralelismo e perpendicularismo, congruência, semelhanças, medição (comprimento, área, volume), sime- trias, entre outros. Acreditamos ser essencial que o professor utilize tecnologias durante as aulas de Geometria, tais como as já citadas anteriormente: a régua, o compasso, os esquadros e o transferidor, ou softwares, as calculadoras, vídeos, entre outros, para ensinar esses conteúdos.

Ao desenvolver atividades com o auxílio do GeoGebra, por exemplo, é possível construir figuras, avaliar se suas propriedades estão sendo verificadas, fazer conjecturas e justificar os seus raciocínios. As figuras podem ser arrastadas na tela do computador sem perder os vínculos estabelecidos na construção. Além disso, é possível realizar construções que com lápis, papel, régua e compasso seriam difíceis, ou no mínimo gerariam imprecisões.

Pesquisas como as de Zulatto (2002), Lovis (2009) e Miranda (2008) apontam que os softwares de Geometria foram facilitadores do aprendizado de conteúdos de Geometria. Na investigação de Lovis (2009), ela observou que - GeoGebra contribuiu para o aprendizado da Geometria Euclidiana, apesar do medo e insegurança que os professores apresentaram durante a sua utilização. Miranda (2008) realizou uma pesquisa com futuros professores de $\mathrm{Ma}$ temática e observou que os alunos em formação adotaram uma postura crítica e autônoma ao uso dos recursos tecnológicos e destacou a necessidade de preparar melhor os professores, ainda nos cursos de licenciatura, para incorporarem o uso de tecnologias na sua prática, em sala de aula. Zulatto (2002) investigou como os professores analisam os softwares de geometria dinâmica e quais as principais potencialidades que eles consideram com relação a esses softwares. Quanto às potencialidades, a autora relata que os professores destacaram as possibilidades de construção, investigação/descobertas, visualização, dinamismo e motivação. 


\section{0 professor, o GeoGebra e a Geo- metria Euclidiana}

Durante a realização do minicurso, observamos atitudes diversas em relação ao uso do GeoGebra. Em geral, os professores sentem fascínio pelo fato de poderem fazer as construções geométricas e de utilizar o software para ensinar Geometria, mas esse fascínio vinha acompanhado de medo e insegurança, principalmente, quando eles eram questionados se levariam os alunos para o laboratório e se arriscariam em uma aula usando um software. Alguns professores deixaram isso evidente nas suas contribuições escritas:

P1 - é uma excelente ferramenta para podermos dinamizar (melhorar) a nossa aula e a nossa prática. Porém, em grande maioria, nós professores não sabemos utilizar essa ferramenta.

P2 - é encantador, uma ferramenta que nos ajudará muito para trabalhar com a Geometria, porém particularmente tenho muitas dificuldades com a tecnologia computadorizada.

P3 - penso que o uso da Geometria por meio da utilização do software GeoGebra é muito bom para nós profissionais. Eu não conhecia, gostei muito, mas para utilizá-lo como ferramenta pretendo estudar mais e muitos treinos em casa.

P4 - o GeoGebra é uma excelente ferramenta para aplicação dos conhecimentos de Geometria, pois proporciona uma aprendizagem mais significativa e prazerosa. É claro, que o professor precisa estudar muito para dominar o software.

Carneiro (2002) destaca que os sentimentos apresentados pelos professores, quanto ao uso de tecnologias, também podem causar uma sensação de desconforto, uma vez que o professor acaba mostrando suas dificuldades para o outro e "o medo aparece acompanhado de outros sentimentos, como o de recusa ou o de insegurança" (CARNEIRO, 2002, p. 55). Essa insegurança já havia sido observada em outro trabalho, Lovis (2009): os professores acham importante o uso de softwares nas aulas de Matemática, mas ainda não sentem segurança necessária para que esse uso seja efetivamente aplicado nas escolas.

Para que as concepções e medos dos professores possam mudar é necessário investir na formação inicial e continuada. Os professores precisam rever e aprender novos conceitos, bem como discutir novas metodologias e instrumentos que auxiliem o aprendizado. Ponte (1998) expõe que:

Para responder aos desafios constantemente renovados que se colocam à escola pela evolução tecnológica, pelo progresso científico e pela mudança social, o professor tem de estar sempre a aprender. O desenvolvimento profissional ao longo de toda a carreira é, hoje em dia, um aspecto marcante da profissão docente. O desenvolvimento profissional permanente é uma necessidade incontornável, mas não deve ser visto como uma mera fatalidade. Pelo contrário, deve ser encarado de modo positivo: a finalidade do desenvolvimento profissional é tornar os professores mais aptos a conduzir um ensino da Matemática adaptado às necessidades e interesses de cada aluno e a contribuir para a melhoria das instituições educativas, realizando-se pessoal e profissionalmente (PONTE, 1998, p. 3-4).

O GeoGebra possui ferramentas excelentes que possibilitam fazer construções geométricas, mostrar resultados da Geometria, mas isso não é suficiente se o professor não souber 
como são feitas as construções e quais são os resultados da Geometria que devem ser utilizados para isso. Muitos professores, conforme observações feitas durante a realização do curso e nas respostas dos questionários mostraram dificuldades com os conhecimentos geométricos. Isso pode ser verificado em vários momentos, dois exemplos explícitos disso, são relatados a seguir.

No decorrer do minicurso os professores aprendiam as ferramentas do GeoGebra conforme elas eram empregadas nas construções realizadas. Tanto o aprendizado da Geometria quanto o do GeoGebra foram abordados de forma simultânea.

Após terem aprendido algumas ferramentas do software, pedimos para que os professores construíssem um quadrado usando o GeoGebra. Inicialmente os professores relataram que não sabiam o suficiente do software para realizar a atividade. Mesmo assim, insistimos para que eles fizessem algumas tentativas.

Neste momento do minicurso ficamos observando e gravando a realização da atividade. Alguns professores usaram a ferramenta polígono, outros construíram segmentos de retas e tentavam alterar a figura, até que esta se tornasse um quadrado; somente um professor usou a ferramenta compasso, na tentativa da construção. Por fim, observamos que nenhum professor conseguiu construir o quadrado, por meio de umas das maneiras possíveis, usando o GeoGebra.

Se a dificuldade estava construir um quadrado no GeoGebra, então pedimos para que os professores nos relatassem como ele construíram um quadrado utilizando uma régua e um compasso. Na descrição da construção do quadrado, somente onze, dos trinta e dois professores conseguiram expressar uma resposta de forma adequada, ou seja, com a constru- ção e as justificativas corretas. É importante observar que era um quadrado qualquer, não foi dado a medida do lado ou a medida de sua diagonal, por exemplo. As respostas dos demais professores - onze - foram incompletas ou confusas. Segue algumas respostas, que consideramos insatisfatórias:

P5 - construa uma reta definida por dois pontos, depois uma paralela, uma perpendicular, colocamos os quatro pontos, usamos o compasso com os pontos das duas retas paralelas, liga por segmento de uma reta.

P6 - com muita dificuldade, usando o compasso ou a régua, marcando dois pontos traçando uma reta e depois outros dois pontos unindo aos outros formando o quadrado.

P7 - traçar um segmento $A B$; ponta seca em $A$, abertura $A B$, faz uma circunferência; ponta seca em $B$, abertura $A B$, faz uma circunferência; as circunferências terão dois pontos de intersecção $C$ e $D$; fazer os segmentos $A C$, $C B, B D$ e $A D$; quadrado $A C B D$.

Na descrição dos professores P5 e P6 percebemos que eles tiveram dificuldades em expressar ao menos uma das maneiras de construir um quadrado. A maneira como a professora P7 descreveu a atividade mostra a construção de um losango e não a de um quadrado. Observamos que outros quatro professores descreveram a construção de um losango como sendo a construção de um quadrado.

A seguir descrevemos a construção de professores que relataram satisfatoriamente maneiras para se construir um quadrado.

P8 - construo uma reta $r$ qualquer definida por dois pontos; construo uma reta s perpendicular a reta $r$; defino o ponto de intersecção entre $r$ e $s$ como ponto $A$; construo uma reta t paralela a $r$ e marco a intersecção de $s$ com t definindo o ponto $\mathrm{B}$; com o compasso, 
transfiro a distância $A B$ para a reta s e defino o ponto $C$; depois transfiro a mesma medida $A B$, para a reta $s$, formando o ponto $D$; como temos duas retas paralelas, as distâncias $A B$ e $C D$ são iguais, formando o quadrado $A B C D$.

P9 - depois de construir uma reta, pega-se uma abertura qualquer sobre esta reta marcando os pontos A e B. Traça-se uma reta perpendicular a essa reta passando por $\mathrm{A} e$ uma outra reta perpendicular passando por B. Pega-se a abertura do compasso $A B$ com centro em $A$ marcando um novo ponto $C$ na primeira reta perpendicular criando assim o ponto C. Novamente com abertura do compasso $A B$ com centro $B$ marca-se o ponto $D$ sobre a segunda reta perpendicular. É só ligar o ponto $\mathrm{C}$ a $\mathrm{D}$ e temos o quadrado.

Na descrição dos professores P8 e P9 eles mostraram ter conhecimento de uma das maneiras de construir um quadrado. Esses professores também tiveram a preocupação em relatar a construção usando uma linguagem adequada. Segue uma maneira de construir um quadrado e uma justificativa para a sua construção, que utiliza o menor número de operações gráficas. Essa construção foi realizada pelo professor que ministrou o minicurso:

Traça-se uma reta suporte $r$, marca-se um ponto A qualquer sobre $r$, e pelo ponto $A$ traça-se uma reta perpendicular $s$. Com uma abertura qualquer do compasso, ponta seca em $A$, marca-se dois pontos $B$ e $D$ nas retas $r$ e $s$, respectivamente. Com a mesma abertura do compasso, ponta seca em $B$, traça-se um arco, ponta seca em $D$, outro arco. A interseção desses dois arcos fornece o ponto $C$, ligando-se os pontos $A, B, C$ e $D$, obtêm-se um quadrado. A demonstração que a construção está correra segue do fato que, por construção, as distâncias entre A e B, B e C, $C$ e $D$ e $D$ e $A$ são iguais, assim, no mínimo temos um losango. Como, por construção, o ângulo DÂB mede $90^{\circ}$, isso nos garante que os outros ângulos também medirão $90^{\circ}$.

Após terem realizada a atividade do quadrado solicitamos aos professores que resolvessem outra atividade, que poderia ser feita em uma folha ou no GeoGebra. A atividade foi a seguinte: na figura a seguir, os segmentos $A B$ e $A C$ medem respectivamente $2 \mathrm{~cm}$ e $3 \mathrm{~cm}$, além disso, sabe-se ainda que $a=\beta$. Encontre a medida do segmento $C D$.

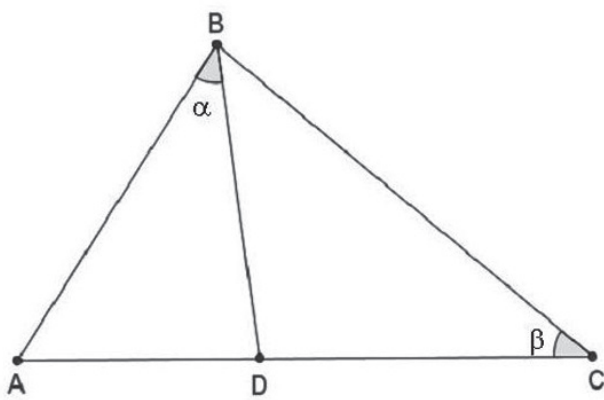

Figura 1: Esboço da atividade.

Fonte: autores

Esta atividade pode ser resolvida utilizando semelhança de triângulos. Constatamos, por meio das discussões e observações realizadas durante o desenvolvimento da atividade, que os professores, em sua totalidade, não conseguiram obter, com justificativas corretas, a solução para o problema. Muitos professores consideraram o triângulo apresentado como sendo um triângulo retângulo, fato que não era um dado do problema, e somente a observação do triângulo não poderia garantir essa característica. Segue a resolução apresentada pelo professor do curso:

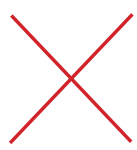


Os triângulos $A B D$ e $A B C$ possuem o ângulo Â em comum, e como por hipótese $a=$ $\beta$, assim temos que os triângulos $A B D$ e $A B C$ são semelhantes. Logo, $\frac{\overline{A B}}{\overline{A D}}=\frac{\overline{A C}}{\overline{A B}}$. Desta forma,

utilizando os dados do problema, concluímos que $3 \overline{\mathrm{AD}}=4$, e assim, $\overline{\mathrm{AD}}=\frac{4}{3}$, portanto, a medida de $C D$ é $3-\frac{4}{3}=\frac{5}{3}$.

Os objetivos dessas atividades foram averiguar se os professores conheciam conceitos de Geometria, envolvidos nas atividades, e se eles percebiam que não bastava conhecer um software geométrico para resolvê-las, e sim ter noções de construções geométricas e conhecimentos geométricos. Como já dissemos, para fazer uso do software é preciso conhecer o conteúdo que se pretende ensinar. Mas, será que o professor tem essa consciência? Ou ele acaba culpando a inabilidade de trabalhar com as novas tecnologias?

O minicurso foi encerrado com uma discussão sobre as atividades desenvolvidas, com e sem o uso do GeoGebra, e sobre a importância do conhecimento do conteúdo matemática a ser ensinado. Durante as discussões observamos, por meio das falas, que os professores perceberam que o desconhecimento de um software não é justificativa para não utilizá-lo. Por fim, os professores relataram que na maioria das vezes, os softwares, no caso os geométricos, facilitam as construções, e nos ajudam, inclusive, a compreender melhor alguns conceitos.

\section{Considerações}

O GeoGebra é uma ferramenta que pode auxiliar o professor no processo de ensino e aprendizagem dos conteúdos de Geometria.
Acreditamos que a tendência em utilizar os recursos tecnológicos na educação será cada vez maior e o professor precisa buscar diferentes formas de inserir esses recursos em suas aulas. Contudo, constatamos que os professores pesquisados carecem de formação que os auxiliem na compreensão e utilização de tecnologias, sejam aquelas disponíveis nas escolas ou não. O fato do professor não ter conhecimento do que pode ser feito com um software de Matemática dificulta ainda mais a inserção dessa ferramenta nas aulas de Matemática.

De acordo com as falas, principalmente dos professores P1, P2, P3 e P4, citadas anteriormente, o GeoGebra pode se constituir em uma ferramenta que auxilia o professor no processo de ensino e aprendizagem de conteúdos de Geometria, porém, o professor precisa conhecer o software e os conteúdos da Geometria que serão utilizados.

Com relação aos conhecimentos de Geometria, percebemos, por meio das duas atividades relatadas, que os professores pesquisados apresentam lacunas no que se refere aos conceitos desse conteúdo. Na primeira atividade, houve dificuldades na construção de um quadrado de lado arbitrário e na segunda atividade observamos que, em sua totalidade, os professores não conseguiram identificar dois triângulos semelhantes em uma figura dada.

Acreditamos que uma das justificativas para a falta de conhecimentos referentes ao conteúdo Geometria pode estar relacionada com a formação dos professores pesquisados, uma vez que a maioria não tem licenciatura plena em Matemática. Diante dos dados obtidos, nos questionamos: como sanar as lacunas no conhecimento geométrico do professor e do uso de tecnologias? Acreditamos que um dos caminhos é investir na formação inicial dos futuros professores e na formação continuada dos 
professores que já estão atuando em sala de aula. Uma alternativa é promover a parceria entre os Núcleos Regionais de Educação com as Instituições de Ensino Superior, com cursos, palestras, entre outros, para auxiliar o professor a sanar as lacunas que ele apresenta.

\section{Referências}

ALMOULOUD, S. Ag et al. A Geometria no ensino fundamental: reflexões sobre uma experiência de formação envolvendo professores e alunos. Revista Brasileira de Educação, n. 27, p. 94-108, 2004.

BORBA, M. de C.; PENTEADO, M. G. Informática e Educação Matemática. 2. ed. Belo Horizonte: Autêntica, 2001, 104p.

BRASIL. Ministério da Educação. Parâmetros Curriculares Nacionais: Matemática terceiro e quarto ciclos do Ensino Fundamental. Brasília, 1998.

CARNEIRO, R. Informática na educação: representações sociais do cotidiano. 2. ed. São Paulo: Cortez, 2002.

LORENZATO, S. Por que não ensinar Geometria? Educação em Revista, ano 3, n. 4, p. 4-13, $1^{\circ}$ sem, 1995.

LOVIS, K. A. Geometria Euclidiana e Geometria Hiperbólica em um Ambiente de Geometria Dinâmica: o que pensam e o que sabem os professores. Maringá, 2009. 148p. Dissertação (Mestrado em Educação para a Ciência e a Matemática) - Universidade Estadual de Maringá.

LÜDKE, M.; ANDRÉ, M. E. D. A. Pesquisa em educação: abordagens qualitativas. São Paulo: EPU, 1986.

MIRANDA, A. O de. Formação de professores para o ensino de Geometria em ambientes informatizados: possibilidades de um trabalho cooperativo. Belo Horizonte, 2008. 92p. Dissertação (Mestrado em Ensino de Ciência e Matemática) - PUC-MG.

NACARATO, A. M. Educação Continuada sob a Perspectiva da Pesquisa-Ação: Currículo em ação de um grupo de professores ao aprender ensinando Geometria. Campinas, 2000. 223p. Tese (Doutorado em Educação) - UNICAMP. 
PALFREY, J.; GASSER, U. Nascidos na era digital: entendendo a primeira geração de nativos digitais. 1. ed. Porto Alegre: Artmed, 2011.

PARANÁ. Secretaria de Estado da Educação. Diretrizes Curriculares de Matemática para a Educação Básica. Curitiba, 2008.

PENTEADO, M. G. Novos atores, novos cenários: discutindo a inserção do computador na profissão docente. In: BICUDO, M. A. V. (Org.) Pesquisa em Educação Matemática. São Paulo: Editora UNESP, 1999.

PONTE, J. P. da. Da formação ao desenvolvimento profissional. Encontro Nacional de Professores de Matemática ProfMat, Lisboa, 1998. Disponível em: http://www.educ.fc.ul.pt/docentes/jponte/artigos_ pt.htm. Acesso em: 25 mar. 2013.

RIBEIRO, M. J. B.; PONTE J. P. da. A formação em novas tecnologias e as concepções e práticas dos professores de Matemática. Quadrante, ano 9, p. 3-26, 2000.

SANTOS, T. S. A Inclusão das Geometrias Não-Euclidianas no Currículo da Educação Básica. Maringá, 2009. 138p. Dissertação (Programa de Pós-Graduação em Educação para a Ciência e a Matemática) UEM.

SOFTWARE GeoGebra. Disponível em: http://www.geogebra.org/. Acesso em: 25 mar. 2013.

ZULATTO, R. B. A. Professores de Matemática que Utilizam Softwares de Geometria Dinâmica: suas características e perspectivas. Rio Claro, 2002. 316p. Dissertação (Mestrado em Educação Matemática) - UNESP.

Submetido para avaliação em 24 de fevereiro de 2012.

Aprovado para publicação em 03 de abril de 2013.

Karla Aparecida Lovis

Universidade Estadual de Maringá. Maringá - PR, Brasil. E-mail: karlalovis@hotmail.com

\section{Valdeni Soliani Frando}

Universidade Estadual de Maringá. Maringá - PR, Brasil. E-mail: vsfranco@uem.br 


\section{APÊNDICE}

\section{Questionário}

Nome:

Série(s)na(s)qual(is)trabalha:

\section{Sobre a sua formação:}

Faculdade na qual se formou:

Curso/anonoqualseformou:

Marque para cada item abaixo com que frequência você faz uso de tecnologias:

\begin{tabular}{|l|l|l|l|}
\hline \multicolumn{1}{|c|}{ Situações de uso } & Nunca & Raramente & Frequentemente \\
\hline Cursos de capacitação & & & \\
\hline Atividades na sala de aula & & & \\
\hline $\begin{array}{l}\text { Atividades no laboratório de informáti- } \\
\text { ca com os alunos }\end{array}$ & & & \\
\hline
\end{tabular}

1 - O que você pensa sobre o aprendizado de Geometria por meio da utilização do GeoGebra?

2 - Descreva como você construiria um quadrado utilizando como ferramentas uma régua não graduada e um compasso.

3 - Na figura a seguir, os segmentos $A B$ e $A C$ medem respectivamente $2 \mathrm{~cm}$ e $3 \mathrm{~cm}$, além disso, sabe-se ainda que $a=\beta$. Encontre a medida do segmento $C D$.

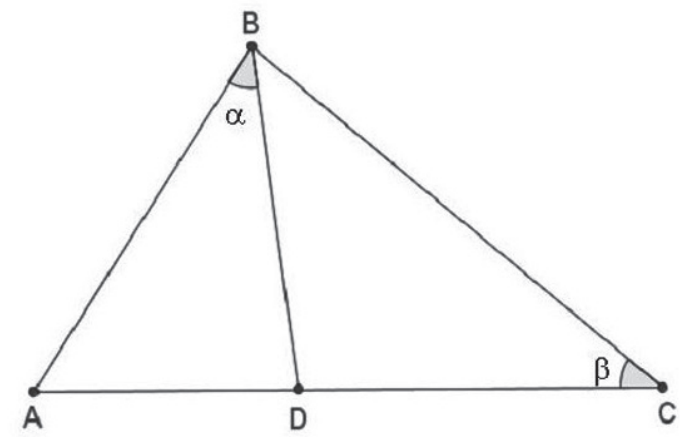

